\title{
Allogeneic GM-CSF-secreting Myeloma Vaccine
}

National Cancer Institute

\section{Source}

National Cancer Institute. Allogeneic GM-CSF-secreting Myeloma Vaccine. NCI

Thesaurus. Code C161652.

An allogeneic plasma cell myeloma vaccine consisting two multiple myeloma cell lines, H929 and U266, admixed with GM-CSF-secreting K562 cells, with potential antineoplastic and immunopotentiating activities. Upon administration, the secreted GM-CSF modulates the proliferation and differentiation of a variety of hematopoietic progenitor cells, with some specificity towards stimulation of leukocyte production, and may reverse treatment-induced neutropenia. This agent also promotes antigen presentation, upregulates antibody-dependent cellular cytotoxicity (ADCC), increases interleukin-2mediated lymphokine-activated killer cell (LAK) function and may augment host antitumoral immunity. For safety, the myeloma cells are irradiated prior to vaccination. 